\begin{tabular}{|c|c|c|c|}
\hline$\Omega$ & (1) & $\equiv$ & (2) \\
\hline $\begin{array}{l}\text { Monica Fletcher', } \\
\text { Iris Bassi }{ }^{2} \text {, } \\
\text { on behalf of LAM }\end{array}$ & $\begin{array}{l}\text { 'Education for Health, } \\
\text { Warwick, UK } \\
{ }^{2} \text { European LAM Federation } \\
\text { President }\end{array}$ & $\begin{array}{l}\text { M. Fletcher, Education for } \\
\text { Health, The Athenaeum, } \\
\text { 10 Church Street, Warwick, } \\
C_{34} \triangle A B \text {, UK }\end{array}$ & m.fletcher@educationforhealth.org \\
\hline $\begin{array}{l}\text { Europe Patient } \\
\text { organisations }\end{array}$ & & & \\
\hline
\end{tabular}

\title{
Patient voices at the ERS International Congress 20I4: highlighting LAM
}

\section{Strong women fighting for their lung health}

Lymphangioleiomyomatosis (LAM) is a rare disease (the mean \pm SD incidence of LAM per million female population between 2004 and 2008 was $0.31 \pm 0.058$ cases per year in the USA, $0.23 \pm 0.076$ in the UK and $0.37 \pm 0.26$ in Switzerland [1]), which almost exclusively affects women at the stage of their lives where they may start to have children. The condition itself is characterised by the development of lung cysts formed from the proliferation of abnormal smooth muscle cells and chyle-filled cystic lesions in the lymphatic system. The main symptoms of LAM include breathlessness, wheeze, chest tightness and can include cough. Patients with LAM often experience one or more pneumothorax, particularly during pregnancy; and it is the development of these which may indicate a diagnosis of LAM [2].

The impact of LAM is huge: primarily women in the prime of their life with new families and their hopes and expectations for the future being limited by an attack on their lungs. One of the major issues surrounding LAM, as with many other rare diseases, is the lack of awareness amongst healthcare professionals, resulting in a delay from the time of presentation to diagnosis and treatment; a worrying and difficult time for the women struggling to breathe. Following a diagnosis, the situation does not get easier, with much information available on the internet giving the worst-case scenario and a dire prognosis.

However, the women with this disease are strong and determined and they want to find answers to their questions and solutions to their problems. This is why the European Lung Foundation (ELF) was proud to work with the European LAM Federation to hold a workshop at the European Respiratory Society (ERS) International Congress in Munich this September for a wide range of stakeholders in LAM.

The aims of this workshop were:

- to bring together people affected by LAM and people working in the field of LAM to discuss the priorities of patients and potential solutions;

- to reach agreement on the actions needed by patients, healthcare professionals and industry to improve LAM treatment and care in response to the priorities identified in an ELF-led European survey of 572 LAM patients; and

- to identify the information needs of patients and their families and if there is a need for a European guide on living with LAM developed in collaboration with LAM specialists.

The outcomes from the survey carried out prior to the workshop and from the workshop were presented later that day in an ERS symposium at which Iris Bassi, the inspirational
Statement of Interest None declared.
HERMES syllabus link: module B.21.2, F.1 


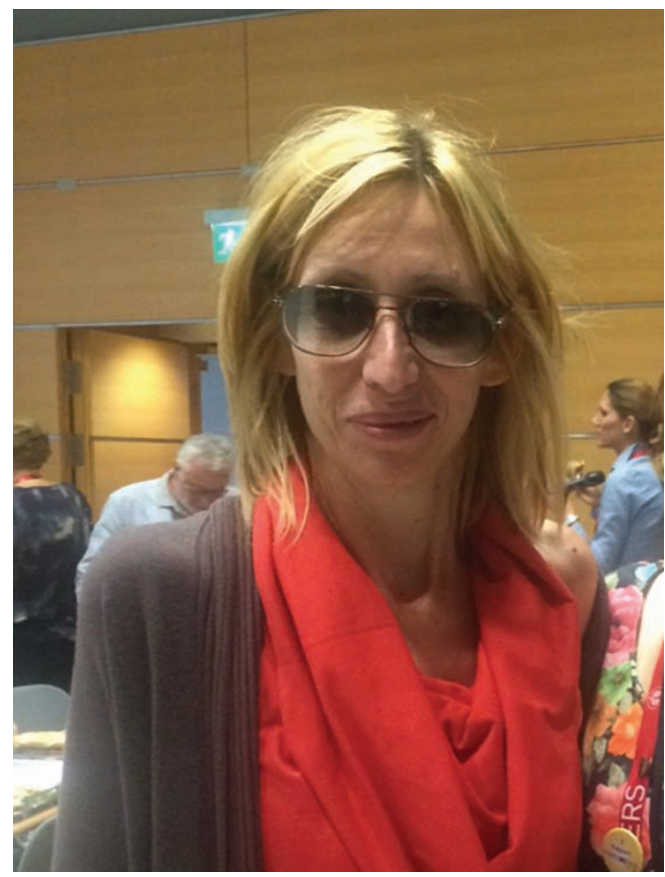

Figure 1

Iris Bassi: European LAM Federation President

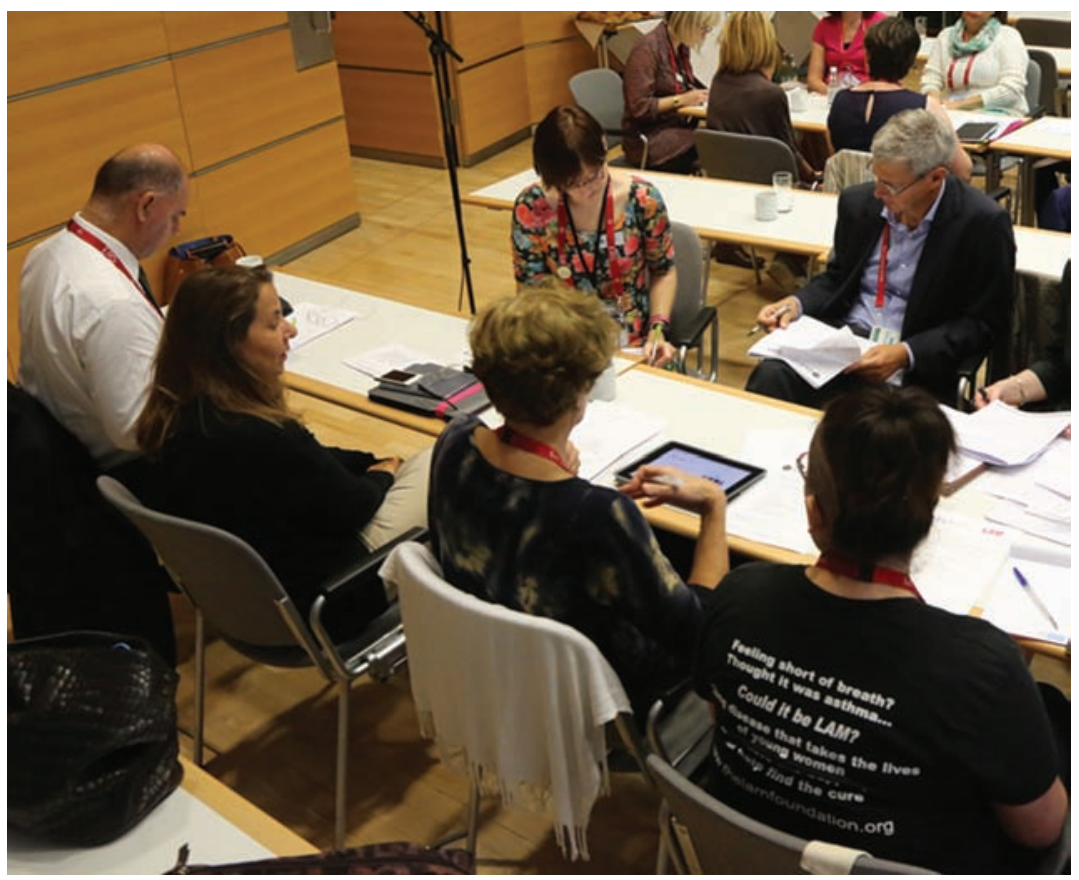

Figure 2

"Feeling short of breath? Thought it was asthma... Could it be LAM?" says the T-shirt of one of the patients at the LAM workshop at the ERS International Congress.
President of the European LAM Federation, diagnosed with LAM in 2007, spoke to a room full of ERS International Congress attendees about the needs and wants of Europe's LAM patients [3]. A full report from this session will be published in 2015 and a patient/healthcare perspective piece featuring Iris and her specialist doctor, Dr Harari, can be found on page 331 of this edition of Breathe [4].

This output from the session will also act as a pilot for the first-ever ELF Patient Priorities project: the production of a recommendations document led by patients/patient organisations in collaboration with ELF. Medical professionals from ERS will join the Patient Priorities steering board to ensure that the medical aspects of the recommendations are correct, but the content and final document will be led by patients and coordinated by ELF.

The aim of Patient Priorities will be:

- to gain insight into the European patient experience;

- identify patients' priorities for treatment and research;

- educate healthcare professionals about the priorities and needs of patients;

- improve services and access to care for patients;

- raise public awareness; and
- further the commitment of ERS to meaningful patient involvement and set a precedent for future patient input into the Society

\section{European and national patient organisations}

In addition to the inspiring LAM event, ELF was joined by representatives from 28 European and 44 national patient organisations throughout the ERS International Congress, representing a huge range of lung conditions. ELF organised a programme of networking events and shared learning opportunities. This included a workshop led by the ERS Junior Members Committee on how patient organisations can produce successful abstracts, posters and presentations at scientific conferences to report on their activities and work. The organisations also met to discuss ELF/ERS activities and how they can all work together with ERS to improve the situation for patients across Europe. ELF and the patient organisations shared a stand in the exhibition area alongside the ERS stand to showcase the impact of patient activities across Europe and their role in supporting patients.

In addition, this year patient speakers took part in symposia on the following topics: 
- Smoking cessation for people with a lung condition

- Home mechanical ventilation

- Patient involvement in EU research projects

- Chronic cough

- Sleep apnoea and continuous positive airway pressure

- Chronic obstructive pulmonary disease and lung transplantation
We are delighted at the now established role of patients at the ERS International Congress, which is set to continue with the support of ELF's network of patient organisations and the strong commitment and support of the ERS. As Dan Smyth took up his post as the first-ever patient Chair of ELF in September this year, we are looking forward to seeing ELF go from strength to strength [5].

\section{References}

1. Harknett EC, Chang WY, Byrnes S, et al. Use of variability in national and regional data to estimate the prevalence of lymphangioleiomyomatosis. QJM 2011; 104: 971-979.

2. Cordier J-F, Ed. Orphan Lung Diseases. ERS Monogr 2011; 54
3. Resources from LAM symposium online: wwW ers-education.org/events/international-congress.aspx? idParent $=132722$

4. LAM: lymphangioleiomyomatosis: the patient and healthcare professional perspective. Breathe; 10: 331-332.

5. Fletcher M. European Lung Foundation: past, present and future. Breathe 2013; 9: 161-163. 